\title{
Factors influencing abstinence, anticipation, and delay of sex among adolescent boys in high-STI prevalence communities
}

\author{
Teresa Cummings, BA ${ }^{1}$, Colette L. Auerswald, MD², and Mary A. Ott, MD, MA ${ }^{1}$ \\ ${ }^{1}$ Department of Pediatrics, Section of Adolescent Medicine, Indiana University School of \\ Medicine, Indianapolis, Indiana \\ 2Department of Pediatrics, UCSF School of Medicine, San Francisco, California
}

\begin{abstract}
Purpose-Abstinence is a core pregnancy and STI prevention strategy. We explore the attitudinal, behavioral, and family contexts relating to abstinence and the decision to delay sex among adolescent boys.

Methods-Adolescent boys ages 14-17 were recruited from community sites using a venuebased sampling method. All eligible boys at venues were invited to participate in an electronic survey. Question items included sexual behaviors, attitudes related to sex, relationships, masculine values, and family contextual items.

Results-We enrolled 667 participants, age 15.7 years, of diverse ethnicity. 252 (38\%) were abstinent. Abstinent participants were younger, less likely to report non-coital behaviors, and reported lower conventional masculine values. Among abstinent participants, $62 \%$ planned to delay sex, while 38\% anticipated sex in the next year. Participants with lower conventional masculine values, and more religious or moral motivations for abstinence were more likely to plan to delay sex.

Discussion-Abstinence among boys is common, even in high STI risk communities. For these boys, abstinence appears to be a complex behavioral decision, influenced by demographic, behavioral, attitudinal and contextual factors such as age, race, non-coital sexual behaviors and masculine values. Understanding the attitudes and contexts of abstinence, including plans to delay sex, can inform the development of public health programs for early fatherhood and STI prevention.
\end{abstract}

\section{Keywords}

adolescent; abstinence; males

\footnotetext{
(C) 2013 Society for Adolescent Medicine. Published by Elsevier Inc. All rights reserved.

This work was submitted as a research presentation for the 2013 Society for Adolescent Medicine Annual Meeting, and was selected as a finalist for the New Investigator's Award

Publisher's Disclaimer: This is a PDF file of an unedited manuscript that has been accepted for publication. As a service to our customers we are providing this early version of the manuscript. The manuscript will undergo copyediting, typesetting, and review of the resulting proof before it is published in its final citable form. Please note that during the production process errors may be discovered which could affect the content, and all legal disclaimers that apply to the journal pertain.
} 
Adolescent boys have high rates of STIs and unintended pregnancies with their partners. The Centers for Disease Control and Prevention (CDC) has identified abstinence as a key pregnancy and STI prevention strategy [1,2], as data suggest that delayed initiation of intercourse decreases the risk of STI and unintended pregnancy [3, 4]. For example, a longitudinal school-based study found that early initiation of sexual intercourse was associated with health risk behaviors, such as a lower rate of condom use and negative health outcomes, such as a disproportionate number of pregnancies [5]. Gender and age are important determinants of abstinence. In the United States 2011 Youth Risk Behavior Survey (YRBS), the prevalence of abstinence in $9^{\text {th }}$ to $12^{\text {th }}$ graders was lower among males than females and that the gap was highest among $9^{\text {th }}$ graders [6]. Much of the abstinence literature focuses either on young women or both sexes equally. There is considerably less data focused on the unique issues related to abstinence in adolescent boys [7]. Existing research suggests that attitudes, particularly those related to gender, sexual and relationship behaviors, and family contexts, may be important to adolescent boys' decisions to be abstinent.

Abstinence can be considered purely a behavior (i.e. not engaging in sexual intercourse or delaying sexual intercourse) or a complex interaction between motivations, attitudes and behaviors [8]. Abstinence behaviors and motivations differ in regards to age, gender, development, and sexual experience [8,9]. For this analysis, we define abstinence as a behavior.

Abstinence is an important decision for early and middle adolescent boys. At age 15, 87\% of boys report being abstinent, but by age 19 , only three out of every ten continue to report abstinence $[10,11]$. There are additionally marked race and ethnicity-related health disparities in both sexual behavior and negative sexual health outcomes, with increased rates of early sexual onset and STIs among African American and Latino boys, and boys from lower income communities $[1,6]$.

Attitudes, beliefs and motivations are important predictors of boys' decision-making about sex and abstinence. Adolescent boys with more positive attitudes and beliefs about abstinence, including moral and gender beliefs, are significantly more likely to delay the initiation of sexual activity $[12,13]$. Moral and religious motivations have been associated with sexual decisions in multiple studies $[8,10,14,15]$. In the nationally representative 2012 National Survey of Family Growth, "Against religion or morals" was the most common reported reason to abstain from sexual intercourse among male youth [10]. Intimacy, readiness, sexual pleasure, and social status have also been associated with decisions to have sex $[9,14]$.

An important distinction among adolescent youth are those that anticipate sex in the near future, and those that plan to delay sex. This differentiated lack of opportunity as opposed to a decision to delay sex. In the longitudinal National Survey of Adolescent Males, the intention to delay sex was associated not only with more positive attitudes, education, and maternal factors, but also with a lower likelihood of initiating sex in the next year (13\% of delayers versus $53 \%$ of anticipators) [15]. 
Research has shown that masculine values are important to sexual decision-making. Masculine values refer to beliefs about how young men should, or should not, present themselves. Conventional masculine values include the beliefs that young men should be self-reliant, physically tough, ready for sex, and not show emotion [16-19]. Homophobia can be an important part of enacting masculinity [16, 17]. Conventional masculine values have been associated with high-risk sexual behavior in nationally representative samples, including more sex partners, using condoms less often, and having less favorable attitudes towards condoms [20]. This analysis examines the role of masculine values in decisions to be abstinent.

Intercourse is only one of a range of sexual behaviors. However, non-coital sexual behaviors such as kissing, having a girlfriend, and genital touching are potentially important to the decision to have intercourse, but relatively understudied [21-23]. Non coital behaviors are more common among sexually experienced versus abstinence boys, and have been shown to precede sex among sexually experienced boys $[15,22,24]$. Non-coital behaviors also distinguished abstinent adolescent boys who anticipated sex or planned to delay sex, with those who planned to initiate sex in the next year reporting more pre-coital experiences than those who planned to delay sex [15].

Communication with parents about sex is also a potentially important contextual influence on of adolescent boys' abstinence decision-making. However, existing studies have shown mixed results. Several studies have demonstrated that adolescents with higher reports of parental communication are more likely to delay sex, report fewer partners, and report using condoms [25-27], and approximately half (46\%) of adolescents report their parents have the greatest influence on their decisions to engage or not in sexual intercourse [28]. However, others have found that adolescent boys' communication with parents was unrelated to sexual decision-making, or even associated with a higher likelihood of sexual experience [29]. Thus, the relationship between parental communication and abstinence requires further study [13].

Sampling approaches are important to our scientific understanding of abstinence. Clinicbased and school-based samples, may over- or underestimate abstinence among boys in communities with the highest rates of STIs [30]. Alternative, community-oriented sampling approaches, such as venue-based or network-based sampling can capture youth in the locations were relationships and sexual decision-making occur [31]. An example of differences based upon sampling is a network-sampling study of urban adolescents, in which only $10 \%$ of boys reported abstinence as compared to the nationally representative YRBS data, where approximately half were sexually abstinent $[32,33]$. Interventions for the most at-risk youth are frequently targeted at communities; a venue-based sampling approach, in which young men are sampled in the community locations where the interventions occur, may be a better estimate of sexual behaviors and STI risk for program planning.

A better understanding of these behavioral, attitudinal, and family influences on younger adolescent boys (14-17 year olds) may inform prevention and intervention opportunities and programs. The purpose of this research is to (1) use venue-based recruitment strategies to describe community rates of abstinence; (2) examine how attitudes, sexual behaviors and 
family communication differ between abstinent and non-abstinent boys; and (3) examine how attitudes, sexual behaviors, and family communication differ by intentions to delay sexual onset in abstinent boys.

\section{METHODS}

\section{Venue Selection}

A venue-based recruitment method was used to target boys in community-based settings in high-STI risk communities [31]. Our target community was defined as the neighborhoods in or adjacent to high STI prevalence zip codes. These zip codes also have high rates of early sexual onset, and were selected so that boys would be actively making decisions about sex. Zip codes were identified through Marion County (Indianapolis) Health Department STI surveillance data. Venues, or community sites where boys "hang out" were identified $(n=249)$ through a community engagement process, including site visits, collaboration with youth-serving agencies, and a youth advisory board. Community-based venues, included parks, recreation sites, apartment complexes, theaters, schools as well as community-based events (such as festivals and church street fairs). Venue were assessed using the following criteria: (1) location is in or adjacent to one of the high-prevalence zip codes; (2) location is frequented by boys between 14 and 17 years old; (3) and the location was safe and provided confidential space for respondents. For school and community-based organizations, we also required (4) permission to recruit from the relevant authorities. Using these criteria, a total of 34 community-based venues were selected out of a possible 249 identified venues.

\section{Recruitment}

After approval by the Indiana University Institutional Review Board (IRB), we recruited 1417 year old boys from the 34 selected venues in Indianapolis, IN. Informed consent was obtained from participants. At each venue, all eligible boys were invited to participate in a 15 to 20 minute electronic survey using an iPad. Survey questions included sexual behaviors, attitudes related to sex, relationships, and family contextual items including communication about sex and relationships. The participants were compensated with a $\$ 20$ gift card.

\section{Measures}

This analysis draws from the Theory of Planned Behavior, examining demographics, attitudes (masculine values, reasons for abstinence), intention to remain abstinent (delayers versus anticipators), and abstinence and sexual behaviors. Adolescents are embedded in families, and we also draw on ecological theory, examining the role of parental communication, a potential influence adolescent sexual decision-making.

We used a behavioral definition of abstinence, identifying abstinent adolescents as those who reported no lifetime sex partners. Abstinent participants were further separated into delayers (those that did not intended to have sex in the next year), and anticipators (those that intended to have sex in the next year) [15]. Non-coital sexual behaviors included having a girlfriend, kissing, touching breasts, and touching genitals (yes/no). Abstinent youth were asked about their intention to have sex in the next year. 
Attitudinal measures included conventional masculine values and reasons for abstinence. Five statements measured masculine values, with response options ranging from strongly disagree to strongly agree. These were adapted from Chu, et al [17, 19], and factor analysis demonstrated two distinct factors, which we labeled conventional and non-conventional masculine values. Conventional masculine values consisted of 3 items (Cronbach's alpha=. 55), with example items including "In a good dating relationship the guy gets his way most of the time" and "Guys should not let it show when their feelings get hurt". Nonconventional masculine values consisted of 2 items (Cronbach's alpha=.59), with example items including "I can respect a guy who backs down from a fight" and "It is ok for a guy to say no to sex.” Among abstinent boys, attitudinal measures of reasons for abstinence [8] were included. Measurement of family contexts, adapted from work by Miller and Forehand $[34,35]$, included parent communication about sex in general (5 items, Cronbach's alpha=. 87), examples "How many times have you talked to your parents or guardian about abstinence?" and "How many times have you talked to your parents or guardian about STDs?" and parent communication about relationships specifically (3 items, Cronbach's alpha=.81), examples "How often have you talked to your parents or guardian about choosing a sexual partner?" and "How often have you talked to your parents or guardian about relationships?".

\section{Data analysis}

Data analysis (using SPSS 20.0) consisted of two sets of analyses, Analysis I comparing abstinent versus non-abstinent participants, and Analysis II comparing abstinent youth who intend to delay sex versus anticipate sex. We first examined different definitions of abstinence (no lifetime sex partners, no vaginal or anal sex, etc.). We conducted sensitivity testing, running analyses with several different definitions of abstinence. There was a $99 \%$ overlap among definitions of abstinence, and we found no significant differences in key findings during sensitivity testing. We chose to define abstinence as having no sexual partners because it was asked early in the survey and was better understood by participants, resulting in less missing data and better data quality. In Analysis I (abstinent vs. nonabstinent), we examined demographic, behavioral, attitudinal and parent communication influences on abstinence. We first examined bivariate relationships using Chi-squares and ttests, and then significant bivariate influences on abstinence were included in a multivariate logistic regression. We report adjusted OR in the results. A similar approach was used in Analysis II (delay vs. anticipate), which examined influences on intention to delay sex. Scales missing 1 or 2 items were imputed. Missing data in Analysis I and II resulted from participants answering "I choose not to answer" as required by the IRB.

\section{RESULTS}

\section{Participants}

We enrolled 667 participants, mean age $=15.7+/-1.1$ years, and of diverse race/ethnicity (49\% African American, 36\% white, 6\% Latino and 9\% other, primarily mixed race). The refusal rate was 37\%. We identified 252 youth (38\%) as abstinent and 405 (62\%) as nonabstinent. Among abstinent participants, 67 (38\%) anticipated sex in the next year, while $110(62 \%)$ planned on delaying sex. 


\section{Analysis I Factors associated with Abstinence}

Abstinent participants, compared to those reporting sexual activity, were younger and more likely to report white race/ethnicity as compared to those reporting sexual activity. Abstinent participants were also significantly less likely to report non-coital behaviors such as touching a partner's genitals or having a partner touch their genitals. Abstinent participants also reported lower conventional and higher non-conventional masculine values. Other noncoital sex behaviors, including having a girlfriend and touching breasts as well as family contextual items, were not associated with abstinence (see Table 1).

\section{Analysis II Factors associated with delay among Abstinent Boys}

Among participants reporting abstinence, 110 (62\%) were categorized as delayers, while 67 $(38 \%)$ were categorized as anticipators based upon their intention to have sex in the next year. Reasons for abstinence were significantly different between delayers and anticipators $(\mathrm{p}<.05)$. The most frequent response of the delayers was "Against religion or morals" (37\%), followed by "Don't want to get a female pregnant or get an STD" (35\%). For the anticipators, "Don't want to get a female pregnant or get an STD" (40\%) was their most frequent response followed by "Not the right time or person" (34\%). Only $6 \%$ of anticipators reported "Against morals or religion."

Using logistic regression we examined factors influencing delay versus anticipation. Significant influences on delay versus anticipation included masculine values and moral motivations. Abstinent participants with higher non-conventional masculine values were more likely to plan to delay sex. Compared to participants who reported that they were abstinent because "it wasn't the right person or right time," participants who reported that they were abstinent because "sex is against my religion or morals" were more likely to plan to delay. Non-coital sex behaviors, including touching of partner's genitals and communication with parents about sex and relationships, were not associated with delaying versus anticipating sex (see Table 2).

\section{DISCUSSION}

Using a venue-based sampling method to access 14-17 year old boys in a high STI prevalence community, we found that abstinence was common, and was associated with age, non-coital sexual behaviors and masculine values. Among abstinent boys, those who planned to delay the onset of sexual activity over the subsequent year were more likely to report having moral concerns about having sexual intercourse and to report lower conventional masculine values. Our study demonstrated that venue-based sampling can successfully be used to identify and engage adolescent boys across a range of behaviors and attitudes, in the same community-based settings targeted by STI prevention programs.

Masculine values were associated with both abstinence and the intention to delay sex. This suggests that interventions that target masculine values may be effective in preventing early onset of sexual behavior. Extending work by our group and others on moral motivations, we additionally observed that, even among adolescent boys in high risk community settings, moral motivations were associated with abstinence and intention to delay sex $[9,10,14,15]$. 
These findings together suggest that public health interventions in the community might increase their effectiveness by addressing masculinity and moral motivations for abstinence.

Consistent with research with other populations of adolescents, fewer non-coital activities were associated with abstinence [36]. Understanding the variety of behaviors in which abstinent youth engage can inform clinicians' counseling.

In our study, neither communication with parents about sex nor relationships was associated with abstinence or intent to delay sex. This lack of effect may be an issue of measurement or power, as we only examined the presence and topics of parental communication using very basic items, rather than the quality, timing, and delivery of these conversations [29, 37].

This study is limited by its cross-sectional design, preventing determination of causality. Our targeted community-based sampling strategy prevent generalization of the results beyond adolescents in similar high STI risk communities. While our response rate was lower than school-based and clinic-based studies, it is not unexpected for a community-based study in which recruitment occurs when participants are engaged in other activities, potentially limiting time, and the sensitivity of the topic, as it might have raised concerns for confidentiality. Finally, and similar to other studies of masculine values among adolescents [38], we have low Cronbach's alpha's for the masculine values scales, suggesting that the construct of masculinity may differ for adolescents compared to adults, and scales that work well in older adolescent and young adult samples may not perform as well with younger boys. Despite these limitations, this study provides a unique glimpse into attitudes, contexts, and non-coital behaviors of abstinent adolescent boys.

Next steps should include a longitudinal study design to look at the timing and trajectories of abstinence and sexual onset by subgroups of boys. Our findings can be used to inform and improve current sexual health counseling techniques for adolescent boys, including the assessment of motivations for abstinence. By understanding the attitudes and context of abstinence, including plans to delay, clinicians and public health professionals can to better target clinical and public health sexual health interventions.

\section{Acknowledgments}

NIH R56 1R56AI090393-01 \& K23-HD049444-01A2

\section{References}

1. Centers for Disease Control and Prevention. Sexually Transmitted Disease Surveillance 2011. Atlanta, GA: U.S. Department of Health and Human Services; Dec. 2012

2. Santelli J, Ott MA, Lyon M, et al. Abstinence-only education policies and programs: a position paper of the Society for Adolescent Medicine. J Adolesc Health. 2006; 38(1):83. [PubMed: 16387257]

3. American Medical Asslciation. Guidelines for Adolescent Preventative Services (GAPS) Reccomendation Monograh. Chicago, IL: Amereican Medical Association; 1997.

4. Hagan, JF.; Shaw, JS.; Duncan, PM. Bright futures: Guidelines for health supervision of infants, children, and adolescents. American Academy of Pediatrics; Elk Grove Village, IL: 2008. 
5. O'Donnell L, O'Donnell CR, Stueve A. Early sexual initiation and subsequent sex-related risks among urban minority youth: the reach for health study. Fam Plann Perspect. 2001:268-275. [PubMed: 11804436]

6. Centers for Disease Control and Prevention. Youth Risk Behavior Surveillance - United States, 2011. MMWR 2012. Jun 8.2012 61(4)

7. Finkel ML, Finkel DJ. Male adolescent sexual behavior, the forgotten partner: a review. J Sch Health. 2009; 53(9):544-547. [PubMed: 6558293]

8. Ott MA, Pfeiffer EJ, Fortenberry JD. Perceptions of sexual abstinence among high-risk early and middle adolescents. J Adolesc Health. 2006; 39(2):192-198. [PubMed: 16857530]

9. Ott MA, Pfeiffer EJ. "That's nasty" to curiosity: Early adolescent cognitions about sexual abstinence. J Adolesc Health. 2009; 44(6):575-581. [PubMed: 19465322]

10. Martinez G, Copen CE, Abma JC. Teenagers in the United States: sexual activity, contraceptive use, and childbearing, 2006-2010 national survey of family growth. Vital Health Stat. 2011 Oct; 23(31):1-35.

11. Abma JC, Martinez GM, Copen CE. Teenagers in the United States: sexual activity, contraceptive use, and childbearing, national survey of family growth 2006-2008. Vital and health statistics Series 23, Data from the National Survey of Family Growth. 2010; (30):1.

12. Carvajal SC, Parcel GS, Basen-Engquist K, et al. Psychosocial predictors of delay of first sexual intercourse by adolescents. Helath Psychol. 1999; 18(5):443.

13. Buhi ER, Goodson P. Predictors of adolescent sexual behavior and intention: a theory-guided systematic review. J Adolesc Health. 2007 Jan; 40(1):4-21. [PubMed: 17185201]

14. Ott MA, Millstein SG, Ofner S, et al. Greater expectations: Adolescents' positive motivations for sex. Perspect Sex Reprod Health. 2006; 38(2):84-89. [PubMed: 16772189]

15. Forste R, Haas DW. The transition of adolescent males to first sexual intercourse: anticipated or delayed? Perspect Sex Reprod Health. 2002:184-190. [PubMed: 12214908]

16. Pleck JH, Sonenstein FL, Ku LC. Attitudes toward male roles among adolescent males: A discriminant validity analysis. Sex Roles. 1994; 30(7):481-501.

17. Chu JY, Porche MV, Tolman DL. The Adolescent Masculinity Ideology in Relationships Scale Development and Validation of a New Measure for Boys. Men Masc. 2005; 8(1):93-115.

18. Smiler AP. Thirty years after the discovery of gender: Psychological concepts and measures of masculinity. Sex Roles. 2004; 50(1-2):15-26.

19. Thompson EH, Pleck JH, Ferrera DL. Men and masculinities: Scales for masculinity ideology and masculinity-related constructs. Sex Roles. 1992; 27(11):573-607. [PubMed: 12322226]

20. Pleck JH, Sonenstein FL, Ku LC. Masculinity ideology: Its impact on adolescent males' heterosexual relationships. J Soc Issues. 2010; 49(3):11-29.

21. Pearson MR, Kholodkov T, Henson JM, et al. Pathways to early coital debut for adolescent girls: A recursive partitioning analysis. J Sex Res. 2012; 49(1):13-26. [PubMed: 21512947]

22. Stanton B, Li X, Black M, et al. Sexual practices and intentions among preadolescent and early adolescent low-income urban African-Americans. Pediatr. 1994; 93(6):966-973.

23. Lindberg LD, Sonfield A, Gemmill A. Reassessing adolescent male sexual and reproductive health in the United States: research and recommendations. Am J Mens Health. 2008; 2(1):40-56. [PubMed: 19477769]

24. Schwartz IM. Sexual activity prior to coital initiation: a comparison between males and females. Arch Sex Behav. 1999; 28(1):63-69. [PubMed: 10097805]

25. Karofsky PS, Zeng L, Kosorok MR. Relationship between adolescent-parental communication and initiation of first intercourse by adolescents. J Adolesc Health. 2001; 28(1):41-45. [PubMed: 11137905]

26. Guilamo-Ramos, V.; Jaccard, J.; Dittus, P. Parental Monitoring of Adolescents: Current Perspectives for Researchers and Practitioners. New York, NY: Columbia University Press; 2010.

27. Weinman ML, Small E, Buzi RS, et al. Risk factors, parental communication, self and peers' beliefs as predictors of condom use among female adolescents attending family planning clinics. Child Adolesc Social Work J. 2008; 25(3):157-170. 
28. Alpert, B. With One Voice 2010: America's Adults and Teens Sound off About Teen Pregnancy. 2010. [cited November 20, 2012]; Available from: http://www.thenationalcampaign.org/ resources/pdf/pubs/wov_2010.pdf

29. Wight D, Williamson L, Henderson M. Parental influences on young people's sexual behaviour: A longitudinal analysis. J Adolesc Health. 2006; 29(4):473-494.

30. Sampson RJ, Morenoff JD, Gannon-Rowley T. Assessing” neighborhood effects": Social processes and new directions in research. Annu Rev Sociol. 2002:443-478.

31. Auerswald CL, Greene K, Minnis A, et al. Qualitative assessment of venues for purposive sampling of hard-to-reach youth: an illustration in a Latino community. Sex Transm Dis. 2004 Feb; 31(2):133-138. [PubMed: 14743078]

32. Rothenberg R, Hoang TDM, Muth SQ, et al. The Atlanta Urban Adolescent Network study: A network view of STD prevalence. Sex Transm Dis. 2007; 34(8):525-531. [PubMed: 17297380]

33. Centers for Disease Control and Prevention. Youth Risk Behavior Surveillance - United States, 2005. MMWR. 2006; 55(SS-5)

34. Miller KS, Kotchick BA, Dorsey S, et al. Family communication about sex: what are parents saying and are their adolescents listening? Fam Plann Perspect. 1998:218-235. [PubMed: 9782044]

35. Forehand R, Armistead L, Long N, et al. Efficacy of a parent-based sexual-risk prevention program for African American preadolescents: a randomized controlled trial. Arch Pediatr Adolesc. 2007; 161(12):1123.

36. Schuster MA, Bell RM, Kanouse DE. The sexual practices of adolescent virgins: genital sexual activities of high school students who have never had vaginal intercourse. Am J Public Health. 1996; 86(11):1570-1576. [PubMed: 8916522]

37. Diiorio C, Kelley M, Hockenberry-Eaton M. Communication about sexual issues: mothers, fathers, and friends. J Adolesc Health. 1999; 24(3):181-189. [PubMed: 10195801]

38. Marcell AV, Ford CA, Pleck JH, et al. Masculine beliefs, parental communication, and male adolescents' health care use. Pediatr. 2007; 119(r4):e966-e975. 
Implications and Contribution

Abstinence is a key component to adolescent STI prevention. This analysis describes the roles of non-coital behavior, masculine values, and moral motivations in abstinence and intention to delay sex among 14-17 year old boys. 
